\title{
Attempts to Answer on the Origin of the High Nitrates Concentrations in Groundwaters of the Sourou Valley in Burkina Faso
}

\author{
Francis Rosillon $^{1 *}$, Boubacar Savadogo ${ }^{2}$, Aminata Kabore ${ }^{3}$, Hortense Bado-Sama ${ }^{4}$, Dayeri Dianou ${ }^{2}$ \\ ${ }^{1}$ Water, Environment, Development Unit, Arlon Campus, University of Liège, Arlon, Belgique \\ ${ }^{2}$ Research Institute for Health Sciences, Ouagadougou, Burkina Faso \\ ${ }^{3}$ Research Center for Biological, Alimentary and Nutritional Sciences, Research and Training Unit, Life and Earth Sciences, \\ University of Ouagadougou, Ouagadougou, Burkina Faso \\ ${ }^{4}$ Convention for the Promotion of a Sustainable Development, Non Governmental Organization, Ouagadougou, Burkina Faso \\ Email: ${ }^{*}$ f.rosillon@ulg.ac.be
}

Received June 3, 2012; revised July 12, 2012; accepted July 21, 2012

\begin{abstract}
Within the framework of the contract of Sourou River, a survey of the groundwater quality was performed through 7 campaigns of water sampling and analysis from 2006 till 2012. The water samples resulted from 23 drillings and 9 wells located in the Sourou Valley. Among the analyzed physico-chemical parameters, the nitrates concentrations observed were worrisome. Out of 32 water sources, 14 (44\%) supplied a nitrates content superior to the WHO threshold value for drinking water $(50 \mathrm{mg} \mathrm{NO} / \mathrm{L}$ ). Very high concentrations, superior to $500 \mathrm{mg} \mathrm{NO} / 3$ with a peak in $860 \mathrm{mg} / \mathrm{L}$, were observed. Given the important variations observed from a sampling point to another, a generalized contamination of the total aquifer was not possible. An individual diagnosis allowed to identify the possible causes of this degradation. Several sources of contamination, in connection with the anthropological activities, were observed near the water facilities (drillings/wells): animal and human wild defecation, presence of nontight latrines, solid waste, wastewater discharges. It is also advisable to wonder about the impact of the dynamite use for digging wells, this one being able to leave nitrates in the water. With regard to the intensive use of water from the strongly contaminated wells and drillings by the rural populations of Sourou, implementing protection areas within which would be eliminated the sources of contamination in addition to health education among populations could improve the situation. Care should also be taken in the use of nitrates explosives for digging new wells or drillings.
\end{abstract}

Keywords: Burkina Faso; Sourou; Groundwaters; Nitrates; Pollution

\section{Introduction}

According to the United Nations Development Program [1], access to safe drinking water in Burkina Faso clearly improved these years with a national rate of water access passed from $18.3 \%$ in 1993 to $66.3 \%$ in 2007. These good performances are the consequence of the efforts undertaken by the country to achieve the Millenium Development Goals (MDG) knowing that water access constitutes a lever of development and a mean to fight against poverty. According to the United Nations, the measures taken led to the reinforcement of the infrastructures of water supply. The network of drinking water adduction which was of 881 kilometers in 1986 reached 3129 kilometers in 2004 while between 2006 and 2007, the projects and programs allowed the realization of approximately 1882 drillings. The situation is undoubtedly variable from one place to another of the

${ }^{*}$ Corresponding author. country, urban environment being privileged compared to rural environment.

Although Burkina Faso already reached the MDG for the access to safe drinking water [1], the situation is not therefore satisfactory, in particular in rural environment where the populations are confronted with the optimal management of the water supply points. Who has not met these drillings installed within the framework of cooperative projects and which, after a few years of operation, break down and aren't repaired?

But beyond the quantitative aspect, it is also advisable to remain vigilant on the level of the water quality consumed by the populations. If in urban environment, distributed water is the object of regular control, it is not the same in rural environment where the indicators of drinking water quality are missing due to the lack of analytical data. An improvement of knowledge is however essential to make the water services more powerful and to rein- 
force the policy for the access to safe water in the country. It is in this direction that in the National Action Plan for Integrated Water Management Resources (APIWRM, 2003), one of measurements relates to the installation of networks for water analysis [2,3].

The present contribution is devoted to the investigation on nitrates, an important physicochemical parameter which characterizes the quality of drinking water for which World Health Organization (WHO) fixed the threshold value of $50 \mathrm{mg} / \mathrm{L}$. This study was conducted from 2006 to 2012 in the Sourou Valley in Burkina Faso. It consisted in evaluating the nitrates contents of water samples from wells and drillings located primarily in the Sourou Province. This survey of groundwaters nitrates contents is part of the data produced by the network of surface and groundwaters quality survey which was initiated within the framework of the contract of the Sourou River [4]. After a first restitution related to the general quality of surface water [5] and of groundwaters [6], it appeared important to examine the problems related to the high nitrates concentrations observed for wells and drillings in this zone.

After the presentation of the context of the study and the methodology used, the results obtained will be presented. We will particularly be interested in the results exceeding the standard of the WHO and more specifically through three case studies in the villages of Yaba, Diouroum and Kiembara. We will try to understand the causes of these raised concentrations of nitrates before proposing some reflections as regards to good practices of management to be implemented in order to solve the problem.

\section{Context of the Study}

\subsection{One Action of the Sourou River's Contract}

This study was realized within the framework of the implementation of a project of river contract in the Sourou's watershed. It constitutes one of the activities registered in the action program of this river contract.

In 2003, through cooperation with the Walloon Region of Belgium, a river contract based on the Walloon model was initiated [4]. This model is an approach of integrated and participatory management which aims at gathering within a river committee of the representatives of all the users of water. This committee has essential mission to define and implement a restoration actions program of the water resources, waterways and their accesses. This program is elaborate according to a consensual approach which takes care to integrate the concerns of each user while improving the environment protection. In Burkina Faso, it was proved that the river contract could also be an issue to fight against desertification and poverty.
This project which has been developed on nearly ten years was framed locally by a Burkinabè NGO, the COPROD (Convention for the promotion of a sustainable development) which dealt with the animation and the coordination of the activities. The Department of Environment of the University of Liege in Belgium ensured the general coordination and the scientific expertise for the account of the Walloon Region in collaboration with the Institute for Health Sciences Research (IRSS) of the Scientific and Technological National Research Center (CNRST) of Ouagadougou.

Considering the operational characteristic of the river contract, many activities were performed at the field [7]. The activities were divided into five sets of themes:

1) Coordination, animation and dialog between actors of water;

2) Improvement of knowledge through the data acquisition and the organization of many formations for the users of water and the local collectivities;

3) Communication, information and sensitization of schools and water users;

4) Restoration of the water resources and the environment which is concretized by an improvement of water access and environment protection (waterways protection and fight against desertification;

5) Income-generating activities in a context of fighting against poverty.

The present study is in line with an improvement of knowledge related to the quality of water resources in the Sourou basin. It also meets one of measures recommended by the APIWRM in the actions field No. 2 "water information system": action 2.2, the implementation of national networks to monitor the water quality, water uses, water requests and the risks. However, it is surprising that the National System on Water Information does not mention nitrates on the list of the basic parameters to consider for the groundwaters quality [8].

\subsection{The Zone of Study}

The Sourou valley is located in the North-West of Burkina Faso, in the area of the Mouhoun loop. The Sourou River takes its source in Mali at the level of Baye. It makes border between Burkina Faso and Mali, by then crossing the Burkina Faso from north to south before joining Mouhoun River at Léri. The Sourou's watershed occupies a surface of $16,200 \mathrm{~km}^{2}$ but it is primarily the central part of the watershed located on the left bank of the river (approximately $5000 \mathrm{~km}^{2}$ ) which is the object of this study (see Figure 1).

The Sourou valley is especially known for its hydroagricultural installations following the erection of dam valves at the junction of Sourou and Mouhoun rivers in 1984. The realization allowed to increase significantly the level of water of the Sourou River, the river draining 


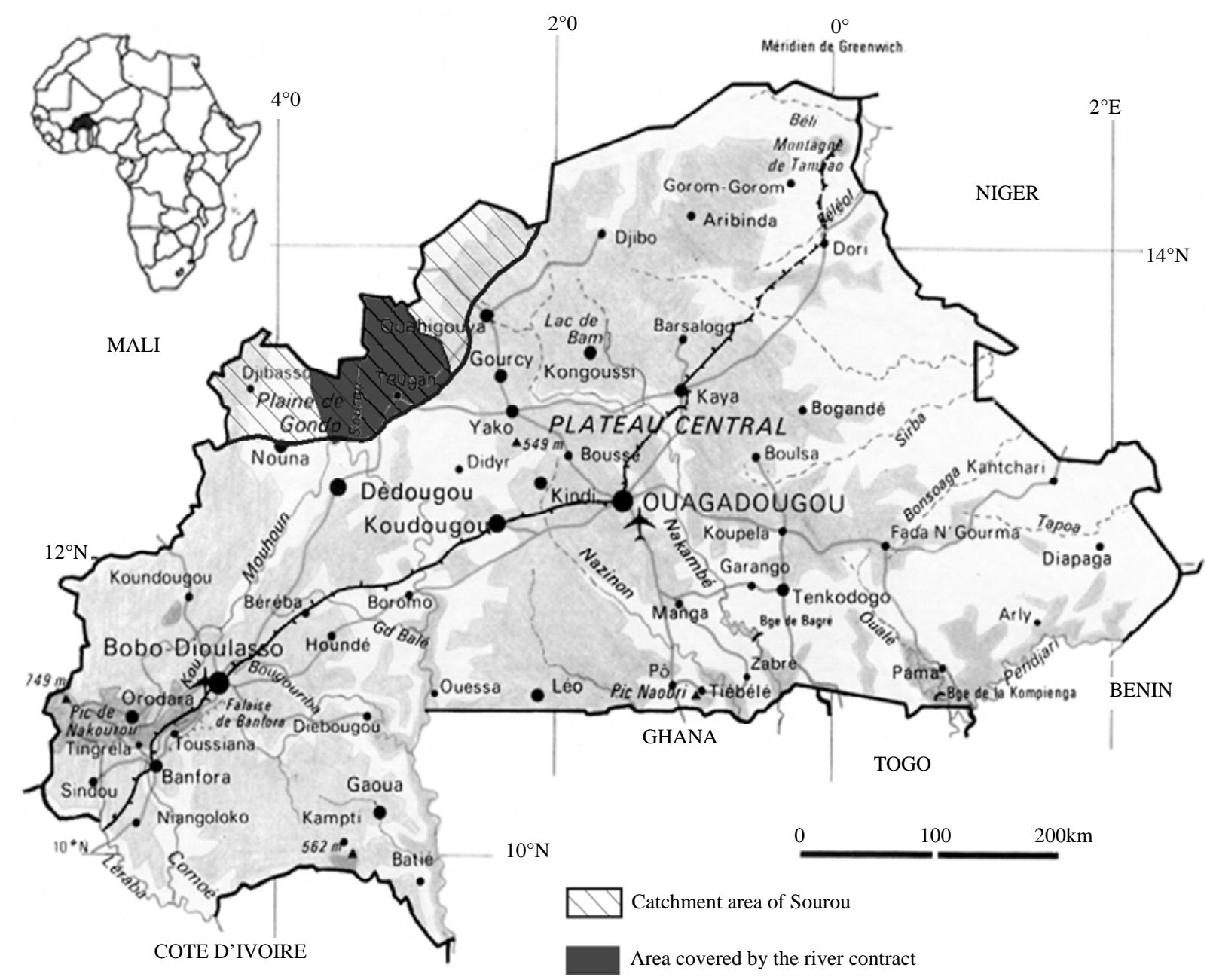

Figure 1. Zone covered by the contract of Sourou River, Burkina Faso.

important quantities of water $\left(600,000,000 \mathrm{~m}^{3}\right)$ through the valley [5]. This availability of water thus allowed the creation of irrigated perimeters, making the Sourou Valley an important agricultural production zone.

Currently, the irrigated perimeters extend on a surface of 3200 ha and are managed under the direction of the Sourou Valley Development Authority (SVDA). The SVDA also envisages to extend the irrigated perimeters area with a new additional zone of 2033 ha. The Sourou valley thus constitutes an important agrarian production zone benefitting the whole country. Onion, tomato, rice, corn, cabbages, lettuces, ... are produced in Sourou. Irrigated wheat cultures were also developed within the framework of cooperation with Morocco. Unfortunately the collected quantities not reaching the envisaged outputs, the culture of wheat was abandoned. The slopes of sprinkling to after the abandonment can still be observed at the field. The activities in the valley are thus directed towards the exploitation of the irrigated perimeters. Elsewhere, they are traditional cultures (millet, sorghum, niebe, ...) not irrigated which are installed. The farmers also supplement their incomes through activities of cattle, sheep and goats breeding, from some heads of cattle per family to herds which can be very important.

Water access for Sourou populations is possible, from various sources of supply, primarily from groundwaters but certain insular villages or close to the river use surface water. Except for some more important localities like Tougan, chief town of the Sourou Province, which profits from a partial system of water adduction, the rural populations generally feed on from water tanks or traditional wells to a relatively dense network of drillings installed by NGO within the framework of cooperative projects or programs supported by the State, in particular by the second Soils Management National Plan (SMNP 2).

The availability of groundwater is rather stable. The Sourou aquifer system is located in a sedimentary zone and consists of hard stones represented by sandstones and limestone-dolomites which can be crossed by faults. The thickness of the aquiferous sandstones is estimated to a hundred meters [9]. The depth of drillings is about a 
sixty meters in the zone of this study. The water level in the traditional wells is variable from one site to another, the depth being of approximately 10 to $20 \mathrm{~m}$. The refill of the aquifer can be established through a slow infiltration in the subsoil. This diffuse refill, could be supplemented by a preferential water flow through fractured zones.

Within the framework of the Sourou river contract, an inventory of wells and drillings were carried out. This inventory identified many nonfunctional works which were the object of repair within the framework of this river contract. More than 100 works were thus given back in activity. Once repairs carried out, it appeared convenient to check the distributed water quality. If initially, the repaired drillings were the object of analysis, thereafter, directed by the nitrates problem, other samplings were carried out.

\section{Material and Methods}

\subsection{Sampling and Field Information Gathering}

The network of groundwater resources analysis consisted of 32 control points along with 23 drillings and 9 wells (traditional or modern, large diameter wells). Seven samplings campaigns were carried out from 2006 to 2012 (see Table 1). Six of the campaigns were conducted in dry season, and one in rain season. A total of 95 samples were taken and analyzed during the campaigns. Samples collected at the field were preserved at $4^{\circ} \mathrm{C}$ in cool boxes, carried to the National Laboratory for Water Analysis in Ouagadougou and stored in a refrigerator before analysis. Some samples were blocked by the addition of mercuric chloride and analysed in Belgium at the laboratory of water resources of the Department of Environment, University of Liege. In addition to nitrates, the samples were also analyzed for other physicochemical parameters $(\mathrm{pH}$, conductivity, turbidity, hardness, ions, $\mathrm{NH}_{4}, \mathrm{PO}_{4}$ ) and for microbiological indicators (fecal contamination indicators: Escherichia coli, Fecal coliforms and Fecal enterocoques) [6].

During sampling, ground observations, supplemented by information collected from water users and local authorities, fed the reflection in order to try to identify the potential sources of contamination.

\subsection{Analysis Method}

The analyses were carried out by the National Laboratory for Water Analysis of the Ministry of Environment in Ouagadougou, in the 2 - 3 days following sampling. Meanwhile, the samples were preserved at $4^{\circ}$. Proportioning is carried out by molecular absorption spectrophotometry through nitrates reduction in nitrites by cadmium (spectro Hach DR2400 method 8171). The nitrites formed are proportioned by diazotization of the sulphanilamide which in the presence of $\mathrm{N}$-ethylenediamine forms a coloured complex [10].

At the laboratory of the Environment Department of the University of Liege in Belgium, the standard NF IN ISO 13395 by analysis in flow and spectrophotometric detection after diazotization was the method applied.

In addition, a rapid semi-quantitative test nitrates was carried out at the field by the use of Merckoquant strips. This test provided a rather good estimate of the nitrates concentrations in water [11].

\section{Results and Discussion}

The average nitrates contents observed during the whole campaigns are presented in Tables $\mathbf{2}$ and $\mathbf{3}$ for drillings and wells. A great variation in the values obtained can be observed which ranged from 1 to $860 \mathrm{mg} \mathrm{NO} / \mathrm{L}$. Important variations can also be observed between two works very closely located. Sometimes for less than one kilometer between two works, important differences can be noted. It does not appear to be a generalized contamination of the Sourou aquifer but localized situations. For a same work, the nitrates concentration is generally stable from one campaign to another, except where the values are high (see the studies of typical cases hereafter).

Whereas many wells and drillings respect the WHO standard of $50 \mathrm{mg} \mathrm{NO}_{3} / \mathrm{L}$, very high nitrates concentrations were recorded at certain places. Thus, the quality of

Table 1. Campaigns of water sampling and samples collected.

\begin{tabular}{cccccc}
\hline No. campaign & Period & Season & Number of samples & Number of well sample & Number of drilling sample \\
\hline 1 & $18 / 10 / 2006$ & Rain (end) & 3 & & 3 \\
2 & $25-30 / 11 / 2007$ & Dry & 15 & 5 & 10 \\
3 & $24-28 / 02 / 2008$ & Dry & 14 & 4 & 10 \\
4 & $6-9 / 06 / 2008$ & Rain & 14 & 5 & 10 \\
5 & $12-13 / 12 / 2009$ & Dry & 18 & 4 & 13 \\
6 & $17-18 / 01 / 2011$ & Dry & 15 & 7 & 9 \\
7 & $19-21 / 01 / 2012$ & Dry & 16 & 29 (9 controls) & 66 (23 controls) \\
Total & & & 95 & &
\end{tabular}


Table 2. Nitrates content in drillings samples (average results).

\begin{tabular}{|c|c|c|c|}
\hline Locality & Drilling name & Number of samples & Nitrates contents (mg NO $3 / \mathrm{L}$ ) \\
\hline Kouy & COPROD & 3 & 18 \\
\hline Sono & Dispensaire & 4 & 8 \\
\hline Kassoum & CEG & 6 & 4.5 \\
\hline Wawara & COPROD & 6 & 4 \\
\hline Dioroum & COPROD & 5 & 648 \\
\hline Dioroum & Mosquée & 1 & 1 \\
\hline Kassoum & Ecole & 3 & 14 \\
\hline Niassan & Dispensaire & 4 & 15 \\
\hline Niassan & AMVS & 4 & 13.5 \\
\hline Di & Caisse populaire & 6 & 119 \\
\hline Yaba & Dispensaire & 4 & 115 \\
\hline Bassan & Bassan & 1 & 45 \\
\hline Diélé & Dièlé & 1 & 20 \\
\hline Bonro & Bonro & 1 & 3 \\
\hline Bourgou & COPROD 1 & 1 & 150 \\
\hline Bourgou & COPROD 2 & 1 & 309 \\
\hline Dian & Dian & 2 & 74 \\
\hline Guiédougou & Ecole & 3 & 19 \\
\hline Boaré & Ecole & 2 & 11.5 \\
\hline Kiembara & PNGT 2 & 3 & 137 \\
\hline Kiembara & $\mathrm{AEP}$ & 2 & 69 \\
\hline Lankoé & Ecole A & 2 & 84 \\
\hline Lankoé & Rimaélé & 1 & 17 \\
\hline Total & 23 drillings & 66 samples & \\
\hline
\end{tabular}

Table 3. Nitrates content in wells samples (average results).

\begin{tabular}{cccc}
\hline Locality & Well name & Number of sample & Nitrates content $\left(\mathrm{mg} \mathrm{NO}_{3} / \mathrm{L}\right)$ \\
\hline Kouy & Mosquée & 6 & 22.5 \\
Kouy & Mission & 1 & 263 \\
Sono & Sono centre & 4 & 44.5 \\
Kassoum & Marché & 4 & 15 \\
Diouroum & Diouroum 1 & 1 & 205 \\
Diouroum & PNGT 2 & 6 & 61 \\
Yaba & Dispensaire & 3 & 143 \\
Kiembara & Mongolo & 3 & 201 \\
Bouaré & Ecole & 1 & 25 \\
Total & 9 wells & 29 samples & \\
\hline
\end{tabular}


water from the COPROD drilling in Diouroum is particularly worrying with a peak of $860 \mathrm{mg} \mathrm{NO}_{3} / \mathrm{L}$ observed during campaign No. 3 (February 2008). To a lesser extent, but however with always raised concentrations, drillings of Di, Yaba, Bourgou and Kiembara presented values ranging from 100 to $200 \mathrm{mg} \mathrm{NO} / / \mathrm{L}$. Out of the 23 analyzed drillings, the WHO threshold value was exceeded for 9 , which corresponds to $39 \%$ of nonconformity (see Figure 2).

Concerning the wells, the maximum concentrations seem less lower than in drillings. However, raised concentrations were observed at Kouy, Yaba, Kiembara and Diouroum. 5 wells out of 9 delivered water with nitrates exceeding the WHO standard, which corresponded to $55 \%$ of nonconformity (see Figure 3).

Other parameters were analyzed in the framework of the contract of Sourou river activities [6] and nitrates did not appear to be the only factor of disturbance. Whereas the ammonium $\left(\mathrm{NH}_{4}\right)$ contents were relatively low for all the works, with concentrations generally lower than 0.5 mg $\mathrm{NH}_{4} / \mathrm{L}$, high concentrations of fecal contamination indicators (100 to more than 1000 Escherichia coli/100 $\mathrm{ml}$ ) were observed for wells samples. On the other hand, drillings globally respected the WHO standard for this indicator (0 Escherichia coli/100 ml). We could not connect the nitrates contents with these fecal contaminations.

High percentages of nitrates in groundwaters were previously observed in the subregion and in Burkina Faso. In the subregion, Mali is also confronted to nitrates concentrations much higher than the WHO standard, according to the Ministry of Energy, Mines and Water [12] of this country, the situation indicates a local pollution of the water supply points. In Senegal, concentrations exceeding $500 \mathrm{mg} \mathrm{NO} / \mathrm{L}$ were observed for the aquifer of quaternary sands in the area of Dakar at the time of campaigns conducted in 1987, 1988, 1995 and 1996 [13]. According to the authors of the study, the contamination of the aquifer by nitrates results primarily from horizontal and vertical flows related to nontight family latrines and organic waste deposits. Moreover, Fall [14] reported values from 165 to $873 \mathrm{mg} \mathrm{NO} / \mathrm{L}$ in 7

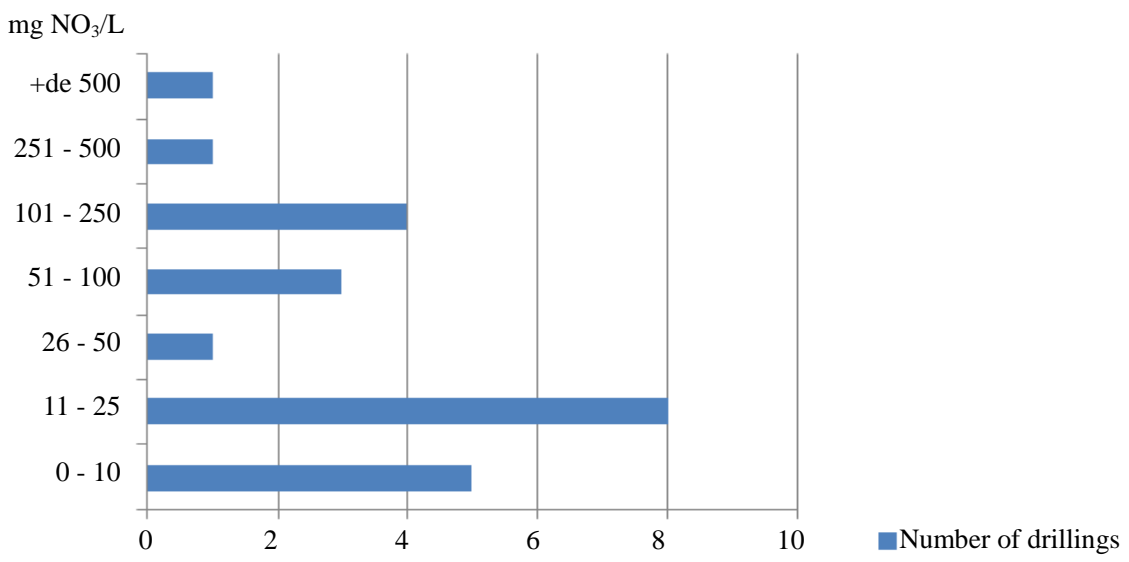

Figure 2. Nitrates contents (per classes) in drillings water samples.

$\mathrm{mg} \mathrm{NO}_{3} / \mathrm{L}$

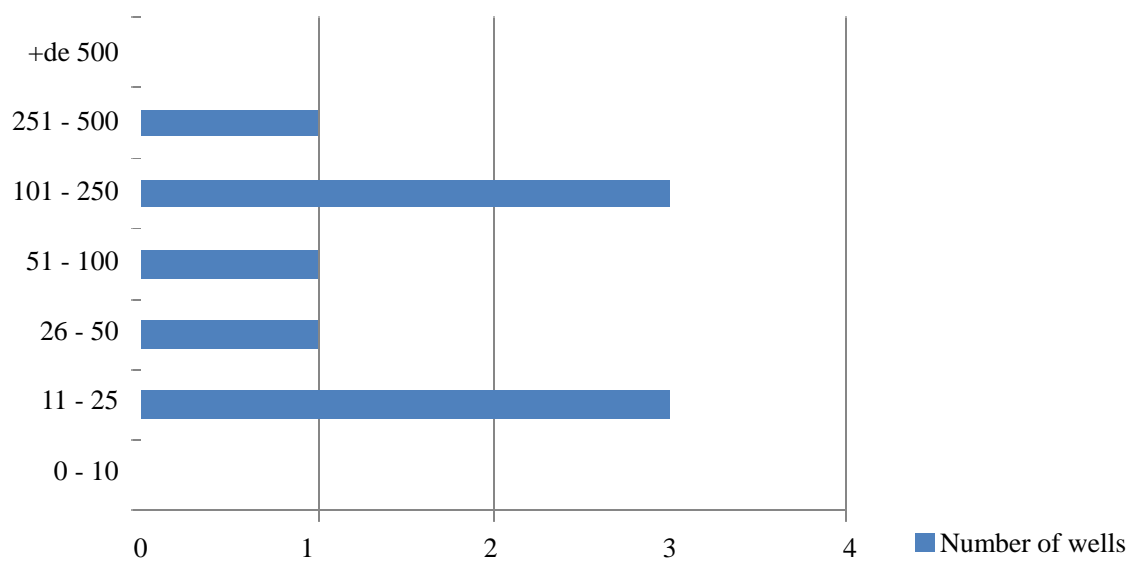

Figure 3. Nitrates contents (per classes) in wells water samples. 
private wells of the town of Pikine, these analyses having been realized in 1992 by the Institute of Sciences of the Environment of Dakar.

At the country level, the National Water Information System (NWIS) of the DGIRH [15] through the follow-up network of water quality evoked raised nitrates concentrations, particularly in the urban centres. According to the design and implementation plan of the NWIS, these results could due to the insufficiency of sanitation and sewerage systems, but we are here in rural environment.

Concerning the Sourou zone, concentrations higher than $100 \mathrm{mg}$ of nitrates per liter were announced by the information system AQUASTAT of FAO [16] in the areas of Mouhoun and Sourou. In addition, two campaigns of water analysis were carried out in May and August 2006 by Nabayaogo [17] within the framework of a study on the impact of the Sourou valley agricultural management on the water resources and the ecosystems. Only some drillings and wells located in the village of Niassan and on the riverside were subjected to analysis. Nitrates contents from 2.7 to $37.2 \mathrm{mg} \mathrm{NO}_{3} / \mathrm{L}$ were observed in Niassan village by the author and correspond approximately to the range of values recorded in this same village during the present study (10 to $23.4 \mathrm{mg}$ $\left.\mathrm{NO}_{3} / \mathrm{L}\right)$.

A study of the CIRAD [18] concludes that the pollution risk of the aquifer by nitrates of agricultural origin is nearly zero in the Sourou valley (zone of $\mathrm{Di}$ ). On the other hand, concentrations reaching $41 \mathrm{mg} \mathrm{NO}_{3} / \mathrm{L}$ were evidenced at the beginning of rainy season in the Sourou river, particularly downstream Di village, within the framework of this project. These nitrates could be due to the cultivation practices related to the production of tomato and onions at this place [5].

For the nitrates concentrations in groundwater exceeding sometimes at a large extent the WHO threshold value of $50 \mathrm{mg} \mathrm{NO}_{3} / \mathrm{L}$, what could be the sources of contamination in the Sourou valley? After rejecting the possibility of a natural origin, we tried to identify the anthropic causes which could explain these high rates of nitrates through field investigations at the respective sites.

Globally, at the selected sites, various potential sources of nitrates can be observed. Concerning diffuse pollution, the important cattle near the water supply points leads to deposits of defecation products in abundance, in addition to that of human origin. It is particularly the case at Diouroum village where the ground is strewn with excrements. In addition, specific organic matter deposits such as dunghills and composting areas can also generate rejections of nutrients. Latrines, although not very widespread in the Sourou villages can also punctually influence the quality of water (case of Yaba village), particularly in fractured zones where a fast contamination of the aquifer is possible.

Concerning nitrates coming from agricultural inputs cultures, since most of the water supply points are far away from the hydro-agricultural perimeters, we could not establish a connection between the fertilizers used and the contamination of groundwaters. Moreover, samples collected from Niassan village, next to the irrigated perimeters presented nitrates concentrations lower than the WHO standard.

It has also been announced that the digging of certain drillings and wells in hard sandstone made up required at certain places the use of dynamite (case of the village of Diouroum hereafter) which could be a source of nitrates release in water.

From the tracks evoked above, it appears difficult to generalize the situation to the whole area in which the variations are very important from one point to another. Within a few kilometers distance, we observed very different nitrates contents, sometimes even within the same village with concentrations varying from one point to another in significant proportions. In order to better understand the origin of these nitrates, we carried out three case studies in three problematic villages where an in-depth survey was carried out, namely Diouroum and Kiembara in the Sourou Province and Yaba in the Nayala Province. The investigations were performed on several periods from 2007 to 2012.

\subsection{Three Case Studies}

\subsubsection{YABA Village}

The village of Yaba (Province of Nayala, Commune of Yaba) counts 6618 inhabitants according to the 2006 INSD census [19]. This village has a dispensary and a maternity equipped with a drilling and a well with large diameter selected for this study.

The water able in the well was at eight meters depth (measured in January 2012). The well located at a few meters of the dispensary presented nitrates concentrations from 93 to $240 \mathrm{mg} \mathrm{NO} / \mathrm{L}$ between 2007 and 2012. An average nitrates content of $115 \mathrm{mg} / \mathrm{L}$ was observed in the water of the drilling of about sixty meters of depth (see Table 4).

Within a radius of 10 to 20 meters around these water supply points, beside the dispensary and the maternity, two buildings occupied by nontight latrines were identified (see Figure 4). In addition to the function of latrines, these pits collect also the biological liquids coming from the maternity.

The first building located at $15 \mathrm{~m}$ of the well was abandoned since a few years. A new block including two latrines is today in activity. To approximately $100 \mathrm{~m}$ of the well and drilling, is an abandoned cemetery. No wild defecation was observed near the works. 
Table 4. Nitrates concentrations in water samples of Yaba dispensary's drilling and well during the 2007, 2008, 2009 and 2012 campaigns.

\begin{tabular}{cccc}
\hline Sampling source & Period & Nitrates concentration $\left(\mathrm{mg} \mathrm{NO}_{3} / \mathrm{L}\right)$ & Average $\left(\mathrm{mg} \mathrm{NO}_{3} / \mathrm{L}\right)$ \\
\hline \multirow{3}{*}{ Yaba_Drilling } & November 2007 & 122 & 116 \\
& February 2008 & 143 & 115 \\
& June 2008 & 80 & \\
January 2012 & & 240 & \\
& November 2007 & 93 & 97
\end{tabular}

In this case, the latrines can be responsible for these the raised concentrations of nitrates. A hydrogeological study should be able to determine the protection zone to set up and in which the activities should be regulated. It is of great importance to have near the health facility a source of water supply and latrines. However, the pits should be perfectly tight and subjected to a frequent draining under control far away the perimeter of protection of the well and the drilling.

\subsubsection{DIOUROUM Village}

The village of Diouroum (Province of Sourou, Commune of Tougan) counts in 20062048 inhabitants, essentially farmers and stockbreeders. The three analyzed water supply points are localized in a maximum radius of $1 \mathrm{~km}$ (see Figure 5). The drilling broken down for several years has been restored by the COPROD within the framework of the application of the contract of Sourou river. In 2010, again broken down, it was repaired by the inhabitants of the village. The nitrates concentrations are particularly high, a peak of $860 \mathrm{mg} / \mathrm{L}$ was observed in June 2008. In January 2012, the concentrations remained high but in clear reduction compared to the previous years. The two other points presented low but still worrying nitrates concentrations (see Table 5).

In the neighborhoods of these water supply points, the first observation relates to the important animal defecation, the animals coming to water itself into the basin next to the drilling. At a few hundred meters, one can observed butts, relics of old districts given up with their waste for a hundred years. A nontight dunghill is localised near the well No. 1.

Drilling would have been dug at the beginning of the Nineties. Work was particularly painful and idles because of the hardness of the rock to be bored, dynamite has been employed to come to end from this resistance. The depth of water is about $60 \mathrm{~m}$. Well PNGT 2 was dug in 2005, its depth is of $10 \mathrm{~m}$ (measured in January 2012).

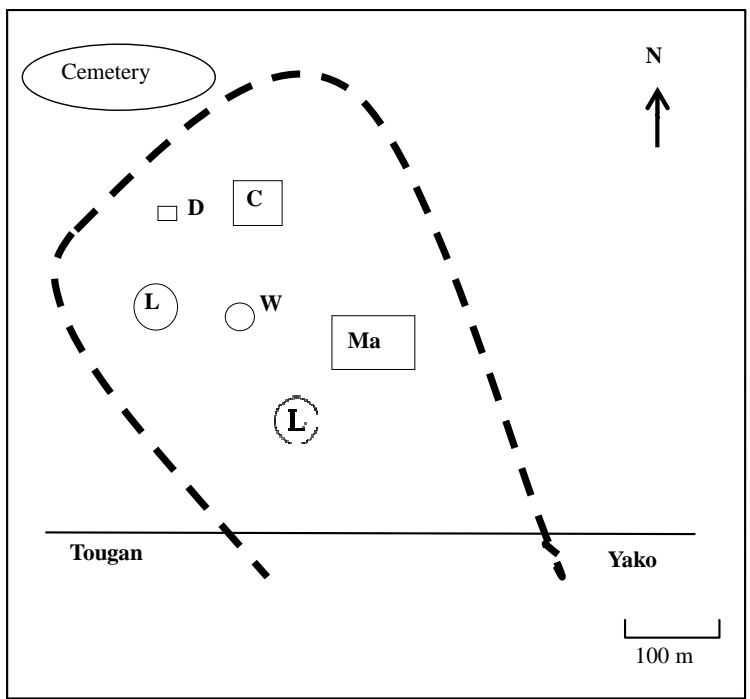

Figure 4. Localization of the water supply points within the health facility/medical center of Yaba and brief description of the close environment. W: Well with large diameter; $D$ : Drilling; L: Latrines; C: Dispensary; Ma: Maternity; - - -: Village; - : Road.

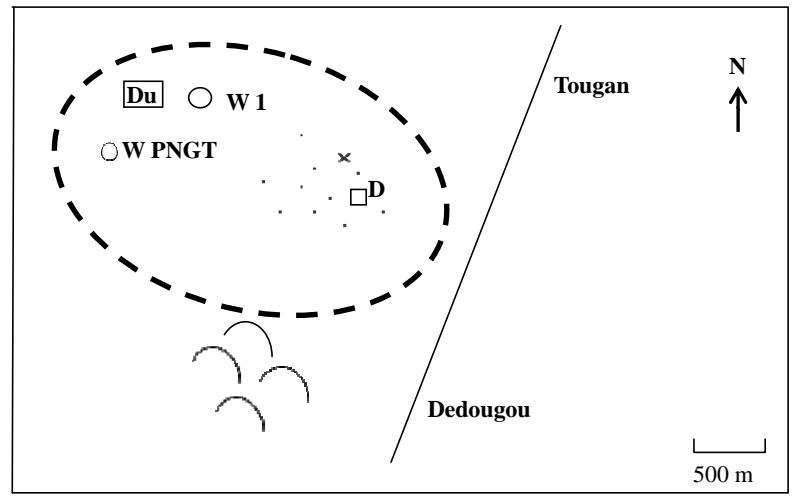

Figure 5. Localization of the three water supply points at Diouroum and description of the close environment; W1: Well with large diameter; W PNGT: Well PNGT 2; D: Drilling; Du: Dunghill; X: Defecation zone; $\frown$ : Old abandoned districts; - - -: Village; —: Road. 
Table 5. Nitrates concentrations in groundwaters at Diouroum.

\begin{tabular}{|c|c|c|c|}
\hline Sampling source & Period & Nitrates concentration $\left(\mathrm{mg} \mathrm{NO}_{3} / \mathrm{L}\right)$ & Average $\left(\mathrm{mg} \mathrm{NO}_{3} / \mathrm{L}\right.$ ) \\
\hline \multirow{5}{*}{ Diouroum—COPROD Drilling } & November 2007 & 750 & \\
\hline & February 2008 & 610 & \\
\hline & June 2008 & 860 & \\
\hline & December 2009 & 703 & \\
\hline & January 2012 & 315 & \\
\hline \multirow{3}{*}{ Diouroum—Well 1} & & & 648 \\
\hline & January 2012 & 205 & 205 \\
\hline & November 2007 & 45 & \\
\hline \multirow{6}{*}{ Diouroum—Well PNGT 2} & February 2008 & 100 & \\
\hline & June 2008 & 37 & \\
\hline & September 2009 & 58 & \\
\hline & January 2011 & 72 & \\
\hline & January 2012 & 54 & \\
\hline & & & 61 \\
\hline
\end{tabular}

Except for the problems of breeding (defecation, manure), we did not observe near these water supply points other elements being able to disturb the quality of water. But what can be the contribution of the use of dynamite (nitroglycerin: $\mathrm{C}_{3} \mathrm{H}_{5}\left(\mathrm{NO}_{3}\right)_{3}$ obtained by nitration with the nitric acid of glycerin)? One can suppose that the nitrates left by dynamite should grow blurred in the course of time. One should keep in mind that the drilling has more than 20 years and that the wells are also contaminated. However, this probable source of contamination should be taken seriously in consideration by avoiding the use nitrated explosives during the operations of drilling.

In addition, if the breeding also contributes to the deterioration of water quality, how to solve this problem? Knowing that the animals need water, is it not appropriate in this precise case to differentiate the water supply points? Some could be dedicated to human consumption, and the others to cattle watering with a sufficient distance in between to avoid disturbances. In this case, a better knowledge of the perimeters to be protected is essential.

\subsubsection{KIEMBARA Village}

The third case of study relates to the commune of Kiembara (Province of Sourou) located on the axis TouganOuahigouya, halfway between these two cities. In 2006, the village counted 4605 inhabitants whose activities were varied: farmers, stockbreeders, truck farming, small shops. Three water supply points were analyzed: a drilling carried out within the framework of the PNGT 2, a traditional well, a fountain supplied with a drilling outside the village. In all the three cases, the nitrates con- centrations were higher than the WHO standard (see Table 6).

PNGT 2 drilling is much attended. Near this drilling, in a radius of 10 to $20 \mathrm{~m}$, dunghills, nontight latrines and wild defecation are observed. Two traditional wells close to the city hall are particularly vulnerable. The immediate surroundings of the wells are soiled by wastewaters and solid wastes. Located on the ground, they directly receive surface waters coming from the surface of the ground. Following the first results communicated to the city hall, a concrete curbstone was installed in 2011. The fountain is fed by a drilling with water tower (see Figure 6) and presents a water of better quality but not respecting however the WHO standard.

Notwithstanding the problem of distances to cover and the crossing of the road Tougan-Ouahigouya, is it not more appropriate to keep the water of the fountain for human consumption and the drilling or traditional wells one for other uses? Is it not also possible to extend the network of water adduction while placing equitably additional fountains throughout the village?

These three cases illustrate the complexity but also the specificity of each situation. They show also the interest of a local analysis, the variations being able to be important within the same village, within a short distance.

\subsection{Impact on Health}

The information obtained from the City hall of Kiembara, the dispensary of Yaba and the hospital of Tougan did not allow to establish a direct relation between the consumption of water with high nitrates concentrations and the consumers' health status. Even if cases of cancers are 
Table 6. Nitrates concentrations in groundwaters at Kiembara.

\begin{tabular}{|c|c|c|c|}
\hline Sampling source & Period & Nitrates concentration $\left(\mathrm{mg} \mathrm{NO}_{3} / \mathrm{L}\right)$ & Average $\left(\mathrm{mg} \mathrm{NO}_{3} / \mathrm{L}\right)$ \\
\hline \multirow{4}{*}{ Kiembara_PNGT 2 Drilling } & December 2009 & 106 & \multirow[b]{4}{*}{137} \\
\hline & Jannuary 2011 & 179 & \\
\hline & January 2012 & 125 & \\
\hline & & & \\
\hline \multirow{4}{*}{ Kiembara_-Traditionnel well } & December 2009 & 171 & \\
\hline & January 2011 & 259 & \multirow{5}{*}{201} \\
\hline & January 2012 & 174 & \\
\hline & & & \\
\hline \multirow{3}{*}{ Kiembara_Fountain } & December 2009 & 71 & \\
\hline & January 2011 & 66 & \\
\hline & & & 69 \\
\hline
\end{tabular}

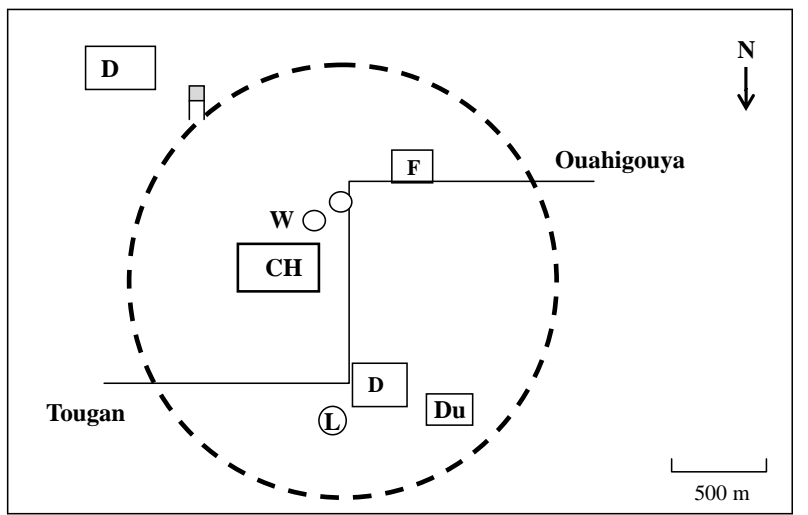

Figure 6. Localization of the three water supply points at Kiembara and brief description of the close environment; W: Traditional well; Du: Dunghill; D: Drilling; CH: City Hall; F: Fountain; ----: Village; L: Latrines; —: Road.

evoked, the patients are transferred towards more important centers for a better assumption of responsibility.

\subsection{Conclusions and Prospects}

From the analysis of the nitrates concentrations in groundwaters of Sourou, it was thus observed that on 32 analyzed water supply points, 14 provided water with nitrates exceeding the WHO threshold value of $50 \mathrm{mg}$ $\mathrm{NO}_{3} / \mathrm{L}$. This proportion corresponds to $44 \%$ of noncomformity. Very high nitrates contents were revealed in some sampling sites.

We tried to understand the origin of these worrying concentrations. Several tracks of contamination were thus evoked near the works, in relation with the anthropic activities: animal and human wild defecation, presence of nontight latrines, presence of pits with dunghill, surfaces of composting, waste deposits, wastewaters rejections, ...
To these possible causes of nitrates pollution, it is appropriate to wonder about the impact of the use of dynamite for digging on the groundwater quality. Many explosives contain in their structure a nitrate radical which could remain in water after drilling. However, the precise diagnosis is not obvious to establish and it requires to be examined case-by-case since the fluctuations of the nitrates contents can be important from one work to another, even if they are very close. The situation is not related to a general contamination of the aquifer of Sourou but born to punctual specific effects which deserve specific observations. Therefore, we examined three typical cases to try to better understand the origin of these nitrates.

The processes of nitrates transfer in the aquifer however deserve to be better documented from an aquifer susceptible to be fractured and sensitive to direct contributions of contaminants. It would be useful to follow nitrate flows from the sources of contamination and to define in particular the transfer times. A refined knowledge of hydrogeology near the works would be also necessary in order to specify the sensitive areas.

But beyond this expertise, it is the rural populations that are confronted to the access to non-safe water. In the case, could it not be advisable to relate water uses to the quality of available water? But that may require longer displacements for certain families towards not contaminated water supply points. Given the difficulty in setting up denitrification processes, could it not be appropriate to define perimeters of protection in which the water sources could be preserved from contamination? In the future, could it not be required to show prudence for the use of nitrated explosives during the digging of new works? 
This contribution which aims at improving knowledge on the quality of water resources in Burkina Faso Registers to the policy of integrated water management to which Burkina Faso subscribed through the APIWRM. These advances in knowledge must be provided to the institutions in charge of the water policy and to the local collectivities, which within the framework of the decentralization, were seen entrusted the responsibility for the natural resources management. It is also appropriate that local participating structures as the Local Water Committees (LWC) catch these problems in order to improve the water services in response to the populations needs. Not to forget that in addition to the quantitative aspect related to water access, water to be provide to populations should be of good quality, with respect to the international standards of drinking water.

\section{REFERENCES}

[1] United Nations, UNDP, "Burkina Faso: Access to Safe Drinking Water Has Improved a Lot,” 2010. http://www.un.org/apps/newsFr/printnewsAr.asp ?nid=23 248

[2] Ministry of Agriculture, Hydraulics and Fishing Resources, "National Action Plan for Integrated Water Resources Management (APIWRM)," Ouagadougou, Burkina Faso, 2003, 62 p.

[3] Ministry of Agriculture, Hydraulics and Fishing Resources, "IWRM 2010 and 2011 Perspectives," Ouagadougou, Burkina Faso, 2011, 29 p.

[4] F. Rosillon, P. Vander Borght and H. Bado-Sama, "River Contract in Wallonia (Belgium) and Its Application for Water Management in the Sourou Valley (Burkina Faso)," Water Sciences and Technology, Vol. 52, No. 9, 2005, pp. 85-93.

[5] D. Dianou, B. Savadogo, D. Zongo, T. Zougouri, J. N. Poda, H. Bado and F. Rosillon, "Surface Waters Quality of the Sourou Valley: The Case of Mouhoun, Sourou, Debe and Gana Rivers in Burkina Faso,” International Journal of Biological and Chemical Sciences, Vol. 5, No. 4, 2011, pp. 1571-1589.

[6] D. Dianou, B. Savadogo, D. Zongo, T. Zougouri, J. N. Poda, H. Bado and F. Rosillon, "Groundwaters Quality in the Sourou Valley,” Not Published, 2012.

[7] H. Bado-Sama and F. Rosillon, "River Contract of Sourou, Outcome of the Actions Program 2003-2008. Report
COPROD/ULG,” 2009, 76 p.

[8] Ministry of Agriculture, Hydraulics and Fishing Resources, "Conception Plan and Implementation of the National Water Information System,” Ouagadougou, Burkina Faso, 2004, 145 p.

[9] Direction of Hydraulics Resources Inventory, Ministry of Water, Burkina Faso, "Leaflet of the Hydrogeological Map of Burkina Faso Scale 1:500,000 Sheet Bobo-Dioulasso,” 1993, $40 \mathrm{p}$.

[10] J. Rodier, "Water Analysis: Natural Waters, Wastewaters, Sea Water,” Ed. Dunod, Paris, 2005, 1384 p.

[11] F. Rosillon, B. Savadogo, A. Kaboré, H. Babo-Sama and D. Dianou, "Estimation of the Nitrates Contents in Waters by Using Reagent Strips: An Environment Education Exercise in the Sourou Valley in Burkina Faso,” Vertig O, Accepted, 2012.

[12] Ministry of Energy, Mines and Water, Republic of Mali, "National Action Plan for Integrated Water Resources Management (First Part): Diagnostic of Water Resources and Their Management Frame,” 2007, 141 p.

[13] A. A. Tandia, C. B. Gaye and A. Faye, "Origin of High Nitrate Levels in the Groundwaters of Quaternary Sands Region Dakar, Senegal,” Sécheresse, Vol. 8, No. 4, 1997, pp. 291-294.

[14] C. Fall, "Analysis of Transfer Operation Sources in Senegal. DEA Memory, FUL, Arlon,” 1996, 143 p.

[15] Direction of Hydraulics Resources Inventory, Ministry of Agriculture, Hydraulics and Fishing Resources, Burkina Faso, "Conception Plan and Implementation of the National Water Information System,” 2004, 135 p.

[16] FAO, "Aquastat, Water and Agriculture FAO Information System: Burkina Faso,” 2005.

http://www.fao.org/nr/water/aquastat/countries_regions/b urkina_faso/indexfra.stm

[17] D. Nabayaogo, “Agricultural Activity in the Sourou Valley: Impact on Water Resources and Ecosystems, Memory, University of Ouagadougou,” 2006, 42 p.

[18] P. Dugué, "Environmental Assessment Study and Development of Sustainable Production Systems in Projects to Support Food Production in Mali and Burkina Faso," Foundation for Agriculture and Rural Life in the world and CIRAD, 2009, $97 \mathrm{p}$.

[19] National Institute of Statistics and Demography (NISD), "Data from the 2006 Census: Distribution of the Resident Population of the Regions by Province, District and Village by Sex and Age Group,” 2006. 